\title{
Diabetic Retinopathy and the Risk Factors in South Sudan: A Six Months Study
}

\author{
Kenneth Lado Sube ${ }^{1, ~ *, ~ J o s e p h ~ D a n i e l ~ L a k o ~}{ }^{2}$, Wani Gindalang Mena ${ }^{3}$, Oromo Francis Seriano ${ }^{1}$, \\ Ader Macar Ader ${ }^{1}$, Richard Lado Lako ${ }^{4}$, Charles Ochero Langoya ${ }^{5}$, Anthony Yousepha Lasuba ${ }^{1}$, \\ Justin Bruno Tongun ${ }^{1}$, Constatine Jervase Yak $^{6}$
}

${ }^{1}$ College of Medicine, University of Juba, Juba, South Sudan

${ }^{2}$ College of Industrial and Applied Sciences, University of Juba, Juba, South Sudan

${ }^{3}$ Department of Ophthalmology, Juba Teaching Hospital, Juba, South Sudan

${ }^{4}$ Directorate of Research and Policy, National Ministry of Health, Juba, South Sudan

${ }^{5}$ College of Medicine and Veterinary Sciences, University of Edinburgh, Edinburgh, UK

${ }^{6}$ Faculty of Medicine, University of Bahr El Ghazal, Wau, South Sudan

\section{Email address:}

ladolojuan@gmail.com (K. L. Sube), jlako24@gmail.com (J. D. Lako), wanigmena@gmail.com (W. G. Mena), oromofrancis19@gmail.com (O. F. Seriano), aderader14@yahoo.com (A. M. Ader), lakorichard08@gmail.com (R. L. Lako), ocherology@yahoo.com (C. O. Langoya), alasuba@yahoo.com (A. Y. Lasuba), tongunmafi@gmail.com (J. B. Tongun), cjervase@rocketmail.com (C. J. Yak)

${ }^{*}$ Corresponding author

\section{To cite this article:}

Kenneth Lado Sube, Joseph Daniel Lako, Wani Gindalang Mena, Oromo Francis Seriano, Ader Macar Ader, Richard Lado Lako, Charles Ochero Langoya, Anthony Yousepha Lasuba, Justin Bruno Tongun, Constatine Jervase Yak. Diabetic Retinopathy and the Risk Factors in South Sudan: A Six Months Study. International Journal of Clinical and Experimental Medical Sciences. Vol. 6, No. 4, 2020 , pp. 79-84. doi: $10.11648 / j$. .jjcems.20200604.15

Received: July 17, 2020; Accepted: July 30, 2020; Published: August 20, 2020

\begin{abstract}
Background: Diabetes Mellitus (DM) remains as one of the global epidemic of Non Communicable Diseases. Diabetic Retinopathy (DR), as one of its complications, has a prevalence of $35.4 \%$ worldwide. Objective: The aim of this study was to determine the prevalence and risk factors for DR among DM patients attending Diabetic Clinic in Malakia Health Center, Juba, South Sudan. Design and Method: This was a prospective, cross-sectional study in which diabetic patients attending Diabetic clinic, Malakia Health Center, were recruited for a period of Six months. All Diabetic patients were included and their demographic data recorded. Clinical data of duration of diabetes and hypertension were noted. Their Visual acuity, Blood pressure, Height, Weight, and Random blood sugar were measured. Eyes were examined and anterior segment diseases diagnosed. Funduscopy was done to determine posterior segment diseases and DR classified. Data were entered into SPSS version 22, analyzed and results expressed in statistical tables. Any result of $p<0.05$ was considered statistically significant. Results: Out of 108 patients and 216 eyes examined, males were 55.6\% (60) and females 44.4\% (48) with ages ranging from 23 to $75 \mathrm{yrs}$, mean age of 51.1yrs (SD+/10.67). Patients with age 46-65 years had the highest $64.8 \%$ (70) and 1835 years as the lowest $6.5 \%$ (8) with $\mathrm{p}>0.05$. Most of these patients $39.8 \%$ (43) were from Kator block residential area with $\mathrm{p}>0.05$. Type I DM were $27.8 \%$ (30) and Type II $72.2 \%$ (78) with $\mathrm{p}>0.05$. DR prevalence was $13 \%$ (28) with NPDR the highest $11.6 \%$ (25) and PDR the lowest $0.5 \%$ (1) with $\mathrm{p}<0.05$. No DR was $64 \%$ (139). DME was $7.4 \%$ (16) and cataract $3.7 \%$ (8). Risk factors for DR among the patients showed that the highest duration of DM was in $>5 \mathrm{yrs} 68.5 \%$ (74) with $\mathrm{p}>0.05$, uncontrolled blood glucose was $81.5 \%$ (88) with $\mathrm{p}>0.05$, known hypertensive was $48.1 \%$ (52), high blood pressure ( $>120 / 80$ $\mathrm{mmHg}$ ) was $43.5 \%$ (41) with $\mathrm{p}>0.05$ and BMI $\left(>30 \mathrm{~kg} / \mathrm{m}^{2}\right.$ was $23.1 \%(25)$ with $\mathrm{p}<0.05$. There were $12 \%(25), 20 \%(44)$, and $68 \%$ (147) eyes blind, visual impairment and normal respectively due DR and the other eye conditions $(\mathrm{p}<0.05)$. Chi-square test showed BMI, BP and visual acuity were the only strongly associated to DR with P values of $0.007,0.001$ and 0.000 respectively. Conclusion: The study had shown, for the first time in South Sudan, the prevalence of DR as 13\% with some of its risk factors. This will influence policy makers to develop strategies to improve management of DM and DR in the country.
\end{abstract}


Keywords: Diabetes Mellitus, Diabetic Retinopathy, Prevalence, Diabetic Clinic, South Sudan

\section{Introduction}

Globally the World Health Organization (WHO) has described Diabetes Mellitus (DM) as the most endocrine disease [1]. Furthermore DM has been considered as a global epidemic of Non communicable diseases due to mainly increasing urbanization which is linked to poor diet, alcohol consumption, lifestyle change within individuals in the community, reduction in physical activities. This is too coupled with the increase in the aging population. About 422 million people worldwide in 2014 had DM with prevalence of $8.5 \%$ within the adult population [2]. It is projected that by 2035 it will increase by $40.3 \%$ to 592 million. In most parts of the world especially developing countries, large number of diabetic patients are not diagnosed and hence are not treated. As a result of this, they often present late to health facilities when they have developed complications of DM. Of these complications, diabetic retinopathy (DR) is the commonest [3] as well as the leading cause of blindness amidst the working class in developed and developing countries [3]. DR is defined as one of the progressive microvascular complications of DM, identified by the signs of retinal ischemia namely: microaneurysms, haemorrhages, cottonwool spots (CWS), venous caliber abnormalities, intraretinal microvascular abnormalities (IRMAs), and neovascularization or signs of increase retinal vascular permeability [4].

Prevalence of DR globally from pooled studies conducted by lee and his group [5] was $35.4 \%$. This was generated from studies based on meta-analysis, population and hospital based data. There was variation of prevalence from one region to another and within the region itself [5]. For instance, DR in Asian countries ( 8 in number) ranges from $15.8 \%$ to $38.3 \%$ with Hon Kong the least and Nepal the highest while in Middle East countries [2] from $28.3 \%$ to $29.6 \%$ with Saudi Arabia with the least and Iran the highest. But in European countries [8] it is from $16.3 \%$ to $48.8 \%$ with Portugal the least and Denmark the highest. In North American countries [2], which is similar to Middle East, it ranges from $27.7 \%$ to $28.5 \%$ with Canada the least and USA the highest. In South American countries [2] it ranges from $7.6 \%$ to $23.1 \%$ with Brazil the least and Peru the highest. In African countries [4] it ranges from $25.8 \%$ to $41.1 \%$ with South Africa the least and Ethiopia the highest while in Oceania countries [3] it ranges from $19 \%$ to $47.1 \%$ with New Zealand the least and Pacific Islands the highest.

These variations may be due to difference in presence and quality of the health care systems, the methods used for screening, type of the research methodology, the age of the patients, type and duration of DM, socioeconomic factors between the studied populations etc. Sivaprasad et al has observed that prevalence rates are usually lower in population base studies than in hospital based ones [6]. In order to reduce the risk of blindness from DR, it has being recommended that there should be early detection and treatment of DR. This should be coupled with improvement of diabetic control services, high quality and affordable methods as well as increasing the general public awareness on the condition and risk of DM.

This study is aimed at determining the prevalence of DR and its risk factors among patients attending diabetic clinic. We believe it will assist the ministry of health and the partners in improving diabetic services in the control in general and DR in eye services in particular.

\section{Materials and Method}

Juba is the capital city of Central Equatoria state (formerly known as Jubek state) as well as the seat for the Government of Republic of South Sudan. It has a population of 230,195 inhabitants and 33,564 households per 2008 census. The city is divided into three administrative areas namely: Juba $(82,346 \quad(35.8 \%)$ inhabitants $), \quad$ Kator $(64,130 \quad(27.9 \%)$ inhabitants) and Muniki (83,719 (36.4\%) inhabitants) blocks. There are three main national hospitals with private hospitals, polyclinics, clinics and Primary health centers. Out of this only one diabetic clinic has been opened since 2016 in Malakia health center, government run facility, by White Nile Charity Company. It composes of a medical officer, laboratory technologist, phleobomist, and diabetic counselor. The center is being funded by the world Diabetic Federation for two programmes namely: raising awareness of the community against DM and capacity building (training health promoters as future diabetic counselors). The clinic delivers laboratory services, and management of DM. All diabetic patients are referred to an ophthalmologist. There is no ophthalmological clinic in the center but one ophthalmologist has volunteered to dedicate a day for examining diabetic patients freely for DR and other eye conditions in his private clinic. There is regular community awareness in the residential areas with an annual campaign during the world diabetic day.

This study was a cross-sectional study conducted in the Malakia diabetic clinic from $1 / 2 / 2017$ to $31 / 7 / 2017$. All patients diagnosed in the clinic as DM were included in the study and their demographic data were recorded in a record form. Anthropometric parameters like weight and height were measured using automated weighing machine combined with height measurer in kilograms $(\mathrm{kg})$ and meters $(\mathrm{m})$ respectively. Body Mass Index (BMI) was calculated for each patient by the formula: Weight $(\mathrm{kg}) / \mathrm{Height}^{2}\left(\mathrm{~m}^{2}\right)$. Patients were classified as underweight, normal weight, overweight, obese and morbidly obese base on their BMI: less than $18.5 \mathrm{~kg} / \mathrm{m}^{2}, 18.5-24.5 \mathrm{~kg} / \mathrm{m}^{2}, 25.0-29.9 \mathrm{~kg} / \mathrm{m}^{2}, 30.0$ $39.9 \mathrm{~kg} / \mathrm{m}^{2}$ and $40.0 \mathrm{~kg} / \mathrm{m}^{2}$ ) respectively. Blood pressure (BP) was measured by automated syphingomonometer calibrated in $\mathrm{mmHg}$. Patients whose BP was more than $120 / 80 \mathrm{mmHg}$ 
were considered as hypertensive. Patients were considered as known hypertensive if they were previously diagnosed by a medical professional and on antihypertensive medications. Duration of DM was calculated from the time when the patient was diagnosed to the day $\mathrm{s}$ /he was seen by the research team and the period corrected to the nearest years. More over patients were recognized as type I DM if it was diagnosed before the age of 30 yrs and using insulin. While type II DM if it was diagnosed after the age of $30 \mathrm{yrs}$ and on oral antiglycaemic medications. Random blood glucose was measured for each patient and the results were categorized into: less or $130 \mathrm{mg} / \mathrm{dl}$ as controlled blood glucose and more than $130 \mathrm{mg} / \mathrm{dl}$ as uncontrolled blood glucose.

A comprehensive examination was conducted by measuring the uncorrected and corrected pin hole visual acuity using the Snellen chart. The results were grouped according to WHO classification of vision [7] in which less than $3 / 60$ in the best eye as blindness, less than $6 / 60$ to $3 / 60$, less than $6 / 18$ to $6 / 60$ as visual impairment and more than $6 / 18$ as normal. Anterior segment was examined using slitlamp and the findings recorded. Fundoscopy was done using 90 D Volk after dilating the pupils with $1 \%$ tropicamide eye drop. DR was diagnosed based on characteristic of the lesion defined by the Early Treatment Diabetic Retinopathy Study (ETDRS) [8] if the followings are present: microaneuryms, haemorrhages, CWS, IRMAs, hard exudates, venous beading and new vessels. DR severity was graded as mild nonproliferative DR (MNPDR), moderate (Mod NPDR), severe (SNPDR) and PDR according to the International Clinical Diabetic Retinopathy Disease Severity Scale. Diabetic eye disease (DED) is defined as a condition of complication of DR when there is either vitreous haemorrhage or retinal detachment.

Ethical approval was obtained from the ethical committee of school of medicine and the state ministry of health of
Central Equatoria (previously known as Jubek state).

Results were all entered, cleaned and analyzed using SPSS Version 21 IBM and displayed as descriptive statistics (means, ranges, standard deviation, frequencies and percentages). Chi-square statistics were used to evaluate associations and data were calculated in which if $\mathrm{p}$ is less than 0.05 the results were considered statistically significant.

\section{Results}

Out of 108 patients and 216 eyes examined, males were $55.6 \%(60)$ and females $44.4 \%$ (48) with ages ranging from 23 to $75 \mathrm{yrs}$, mean age of $51.1 \mathrm{yrs}(\mathrm{SD}+/ 10.67)$. Patients with age 46-65 years had the highest $64.8 \%$ (70) and $18-35$ years as the lowest $6.5 \%(8)$ with $\mathrm{p}>0.05$ as shown in Table 1 . Most of these patients $39.8 \%$ (43) were from Kator block residential area with $\mathrm{p}>0.05$ (Table 1). Type I DM were $27.8 \%$ (30) and Type II $72.2 \%$ (78) with $\mathrm{p}>0.05$ as shown in table 2. DR prevalence was $13 \%$ (28) with NPDR the highest $11.6 \%$ (25) and PDR the lowest $0.5 \%$ (1) (Table 2) with $\mathrm{p}<0.05$.

No DR 64\% (139), DME 7.4\% (16), and cataract 3.7\% (8) as shown in Table 2.

Risk factors for DR among the patients showed that the highest duration of DM was in $>5 y$ rs $68.5 \%$ (74) with $p>0.05$, uncontrolled blood glucose was $81.5 \%$ (88) with $\mathrm{p}>0.05$, known hypertensive was $48.1 \%$ (52), high blood pressure $(>120 / 80 \mathrm{mmHg})$ was $43.5 \%$ (41) with $\mathrm{p}>0.05$ and BMI $\left(>30 \mathrm{~kg} / \mathrm{m}^{2}\right) 23.1 \%$ (25) with $\mathrm{p}<0.05$ as shown in table 3 . Table 4 showed that there were $12 \%$ (25), 20\% (44), and 68\% (147) eyes blind, visual impairment and normal respectively due DR and the other eye conditions $(\mathrm{p}<0.05)$.

Evaluation of associations using chi-square test showed BMI, BP and visual acuity are the only strongly associated to DR with $P$ values of $0.007,0.001$ and 0.000 respectively.

Table 1. Demographic characteristics of the Diabetic patients ( $n=108)$ attending Diabetic clinic at Malakia Health Center.

\begin{tabular}{lllll}
\hline Variable & Characteristic & Frequency (n) & Percentage (\%) & P value \\
\hline Sex & Male & 60 & 55.6 \\
Age (years) & Female & 48 & 44.4 & 2.8 \\
& $18-25$ & 3 & 3.7 & 0.115 \\
& $26-35$ & 4 & 21.3 & 41.7 \\
& $36-45$ & 23 & 23.1 & 7.4 \\
Residence & $46-55$ & 45 & 25 & 0.549 \\
& $56-65$ & 25 & 39.8 & 35.2 \\
\hline
\end{tabular}

Table 2. Distribution of types of diabetes mellitus, Diabetic Retinopathies and other eye conditions among the patients attending Diabetic clinic at Malakia Health Center.

\begin{tabular}{llll}
\hline Variable & Characteristic & Frequency (n) & Percentage (\%) \\
\hline Diabetes M & TypeI & 30 & 27.8 \\
& TypeII & 78 & 72.2 \\
DR & No DR & 139 & 64 \\
& MNPDR & 14 & 6.5 \\
& ModNPDR & 4 & 1.9 \\
& SNPDR & 7 & 3.2 \\
& PDR & 1 & 0.5 \\
\hline
\end{tabular}




\begin{tabular}{llll}
\hline Variable & Characteristic & Frequency (n) & Percentage (\%) \\
\hline \multirow{3}{*}{ TOTAL (DR) } & DED & 2 & 0.9 \\
Others & & 28 & 13 \\
& DME & 16 & 7.4 \\
& ARMD & 5 & 2.3 \\
& Cataract & 8 & 3.7 \\
& Glaucoma & 2 & 0.9 \\
& Others $^{*}$ & 18 & 8.4 \\
\hline
\end{tabular}

* Pseudophakia, Dry eye syndrome, Blepharitis, Refractive error and Age related macular degeneration.

Table 3. Shows distribution of risk factors of DR among Diabetic patient attending Diabetic Clinic at Malakia Health Center.

\begin{tabular}{|c|c|c|c|c|}
\hline Variable & Characteristics & Frequency (n) & Percentage (\%) & Pvalue \\
\hline \multirow[t]{4}{*}{ Duration of DM (years) } & $<2$ & 14 & 13 & \\
\hline & $2-<5$ & 20 & 18.5 & \\
\hline & $5-<10$ & 35 & 32.4 & \\
\hline & $>10$ & 39 & 36.1 & 0.439 \\
\hline \multirow[t]{2}{*}{ RBS (mg/dl) } & $<130$ & 20 & 18.5 & \\
\hline & $>130$ & 88 & 81.5 & 0.326 \\
\hline \multirow[t]{2}{*}{ Hypertension } & Positive & 52 & 48.1 & \\
\hline & Negative & 56 & 51.9 & 0.09 \\
\hline \multirow[t]{4}{*}{$\mathrm{BP}(\mathrm{mmHg})$} & $<120 / 80$ & 61 & 56.3 & \\
\hline & $120 / 80-<159 / 90$ & 31 & 34.3 & \\
\hline & $159 / 90-<160 / 100$ & 5 & 4.6 & \\
\hline & $>160 / 100$ & 5 & 4.6 & 0.09 \\
\hline \multirow[t]{5}{*}{$\operatorname{BMI}\left(\mathrm{Kg} / \mathrm{m}^{2}\right)$} & $<18.5$ & 10 & 9.3 & \\
\hline & $18.5-24.9$ & 40 & 37.0 & \\
\hline & $25-29.9$ & 33 & 30.6 & \\
\hline & $30-34.9$ & 20 & 18.5 & \\
\hline & $35-39.9$ & 5 & 4.6 & 0.007 \\
\hline
\end{tabular}

Table 4. Shows distribution of visual acuity against eye diseases among diabetic patients attending diabetic clinic at Malakia Health Center.

\begin{tabular}{lllll}
\hline \multirow{2}{*}{ Diagnosis } & Visual Acuity & & & \\
\cline { 2 - 5 } & Less than or 3/60 & $<\mathbf{6 / 6 0}$ to $\mathbf{3 / 6 0}$ & $<\mathbf{6 / 1 8}$ to 6/60 & $>\mathbf{6 / 1 8}$ \\
\hline No DR & $8(32 \%)$ & $1(4.5 \%)$ & $3(13.6 \%)$ & $57(38.8 \%)$ \\
MPDR & $2(8 \%)$ & $0(0 \%)$ & $4(18.1 \%)$ & $8(5.4 \%)$ \\
ModPDR & $0(0 \%)$ & $1(4.5 \%)$ & $1(4.5 \%)$ & $0(0 \%)$ \\
PDR & $1(4 \%)$ & $1(4.5 \%)$ & $0(0 \%)$ & $0(0 \%)$ \\
DED & $2(8 \%)$ & $0(0 \%)$ & $0(0 \%)$ & $0(0 \%)$ \\
DME & $2(8 \%)$ & $4(18.1 \%)$ & $3(13.6 \%)$ & $3(2 \%)$ \\
Cataract & $4(16 \%)$ & $0(0 \%)$ & $0(0 \%)$ & $1(0.7 \%)$ \\
Glaucoma & $2(8 \%)$ & $0(0 \%)$ & $0(0 \%)$ & $2(1.4 \%)$ \\
Others & $4(16 \%)$ & $15(68 \%)$ & $11(50 \%)$ & $76(51.7 \%)$ \\
Total & 25 & 22 & 22 & 147 \\
\hline
\end{tabular}

$\mathrm{P}=0.000$.

* Pseudophakia, Dry eye syndrome, Blepharitis, Refractive error and Age related macular degeneration.

\section{Discussion}

Diabetes Mellitus (DM) is estimated in Africa to double from 12 million to 24 million in 2030 within the adult population as stated by the International Diabetes Federation (9). This is seen due to increase in urbanization, poor diet, smoking, alcohol intake, change in life style, reduction in physical activities, and increase in aging population. Diabetic retinopathy (DR) as one of the complications of DM, poses itself as a challenge to African countries. This is seen in form of increase in politico-socio-economic in stability, increase in disease burden coupled with poor and weak health systems. In Sub Saharan Africa, DR prevalence ranges from $7 \%$ to $63 \%$ among diabetic patients [10]. This study is intended to highlight on the prevalence of DR and its risk factors in The Republic of South Sudan.
In our study there were $55.6 \%$ males and $44.4 \%$ females. There is slight male preponderance which is not in line with studies done in Nigeria [11, 12]. This is because males are breadwinners and control family resources and therefore they have easy access to health care services. Conversely in parts like Nigeria women play a big role in generating resources to the family. This gives them more opportunity to access health facilities. The main age affected was from 46 to 65 years $(64.8 \%)$. Even though the prevalence is very high, this age group is nearly similar to these studies $[13,14]$. But different from this study [11]. Almost $40 \%$ of the patients were residence of Kator block. This is because the diabetic clinic is easily accessible by patients from kator residential area even though it is located in Juba block. Type II DM 72.2\% were more than type I DM $27.8 \%$. This is similar to study conducted by Umoh et al [11] in Nigeria. Type I DM patients 
normally present as emergency cases in a hospital setting. Apparently type II DM patients are more seen as cold cases places like diabetic center.

The prevalence of DR was $13 \%$. This was the same as studies conducted in Ethiopia 13\% [15] and similar to researches done in Oman 14.4\% [16] but lower than results from Tanzania 27.9\% [17], Saudi Arabia 36.4\% [18], Malawi $50.1 \%$ [19] with Cameroon having the highest 54.1\% and $73.9 \%$ [20]. These disparities especially within the African countries may be due to difference in the study methods used, demographical data, type of DM, duration of DM, culture, availability of the diabetic services in the studied communities and the health seeking behavior. More over our lower prevalence may be due to slow urbanization, slow in change of life style, less westernized diet, increase physical exercise as most of the people cannot afford transport as the country is faced with economical crisis. In our study NPDR $(11.6 \%)$ was higher than PDR $(0.5 \%)$. This is with accordance with the literature [21]. The prevalence of PDR was observed to be lower than the global 7\% [22]. Other studies like in Sudan 1.7\% [14], Nigeria 2\% [12] had documented higher results than ours. Higher prevalence of PDR had being found in some African countries [20, 23, 24] to be associated with complications of DM. Global DME was $6.8 \%$ [21] which was similar to our study $7.4 \%$ but some studies [11] had shown a higher record 32.2\%. DME and PDR are grouped as vision threatening diabetic retinopathy since they are the severe form of DR that compromises with vision. They contribute a lot to blindness in DR. Their presence makes it vital for the ministry of health to set policies for guiding public awareness and clinical management of DM in the country.

Most of the patients $68.5 \%$ in the study had a more 5 years duration of DM even though it was statistically significant $\mathrm{p}>0.05$. Duration of DM of more than 5 years had being found to be strongly associated with DR as shown in most studies (11, 12 and 25). Furthermore un controlled blood glucose do play a role in progression of retinopathy. Interestingly our study had recorded high value of $81.5 \%$ of uncontrolled blood glucose but of no statistical significance. This might be due to a small sample size. High blood pressure $43.5 \%$, BMI $\left(>30 \mathrm{~kg} / \mathrm{m}^{2}\right)$ and visual blindness $12 \%$ were found to strongly associated with DR $(\mathrm{p}<0.05)$. Apart from DR being a complication of DM, some studies have shown that cataract and glaucoma can result from DM. Our study has shown cataract $3.7 \%$ and glaucoma $0.9 \%$ among DM patients attending diabetic clinic at Malakia Health Center.

Limitation of this study is its small size and clinic base study. Furthermore lack of funduscopic retina camera which is more objective than reliance on subjective examination. We could not test for other parameters considered as indicators for risk factors in DR due to lack of funding.

\section{Conclusion}

This study had, for the first time, shown prevalence of DR as $13 \%$ with duration of $\mathrm{DM}, \mathrm{BP}$, and $\mathrm{BMI}$ as the risk factors in the Republic of South Sudan. Moreover we are able to record prevalence of hypertension as $43.5 \%$.

\section{Recommendations}

To fight blindness from DR, early detection and management of DR is recommended. This should be operationalised hand in hand with improvement of diabetic control services, high quality and affordable methods, and increasing the general public awareness on the condition and risk of DM. Base on this, the followings are recommended:

a) There is a need for the Ministry of Health to develop policies for Non Communicable Diseases which includes Diabetes Mellitus.

b) The directorate of eye services should develop programme for diabetic retinopathy in the eye care activities.

c) Training of medical cadres (clinical officers, Nurses, Medical doctors, Physicians) in screening, diagnosing DR and referring those who need consultancy of ophthalmologist should be encouraged. This will improve referral of DM patients to be screen for DR. Eventually will increase the services of DR in country wide.

d) Integrate DM and DR screening in health system.

e) Training of medical cadres as health promoters in health awareness in DM and DR. This will improve health awareness of the community and increase the uptake of health facilities.

f) Improve and expand Diabetic clinic to include a consulting physician, Paediatrician, Surgeon, and Ophthalmologist once or twice a week.

g) Currently the following equipments are absent in the center: slit lamp for examination of patients, Green Laser machine for the management of severe NPDR or PDR or DME, Imaging technology like Optical Coherence Tomography (OCT) and Fluorescent Angiography (FA), Indirect and direct ophthalmoscopes. There is a need for these essential equipments to be purchase by the ministry or any willing partner (e.g. World diabetes federation). Some like lasers, OCT and FFA are not available in any centers in the whole country.

There is a need of conducting a large sample research (at least 2 to $3 \mathrm{yrs}$ ) from the same diabetic center on the same topic in order to have more statistical significant results.

\section{Author Contributions}

Conceptualization: KS, WM, AA, JL, RL, CL, AL and CY.

Data curation: KS, JL and RL.

Formal analysis: KS, WM and RL.

Methodology: KS, WM, AA, JL and RL.

Manuscript writing and revision: KS and WM.

All authors read and approved the final manuscript. 


\section{Conflict of Interest}

The authors declared that there is no conflict of interest.

\section{Acknowledgements}

We would like to thank all staff and patients of Diabetic clinic Malakia Health Center for their assist and support to our team. If not because of them, we would not have succeeded in this study.

\section{References}

[1] Frank Cortez-Floris, Supercourse, Aging and Diabetes mellitus [online] Available form: http://www.pitt.edu/ super1/lecture/lec1921/031.htm.

[2] World Health Organization (WHO), global report on diabetes. 2016: http://www.who.int.

[3] D. Paul Cohen, 2002, Dirty Dozen Research (online) Availablefrom: http://www.cohenresearch.com/reports/isv03-27-02.pdf.

[4] Bandello F, Lattanzio R, Zucchiatti L, Petrazzi G. Nonproliferative Diabetic Retinopathy page 19-63. chapter in book edited by Bandello F, Zarbin MA, Lattanzio R, Zucchiatti I. Clinical strategies in the management of diabetic retinopathy. Published in 2014 by Springer.

[5] Lee R, Wong T Y, and Sabanayagam C. Epidemiology of diabetic retinopathy, diabetic macular edema and related vision loss. Eye and Vision (2015) 2: 17 DOI 10.1186/s40662015-0026-2.

[6] Sivaprasad S, Gupta B, Crosby-Nwaobi R, and Evans J. Prevalence of diabetic Retinopathy in various ethnic groups: A worldwide perspective. Surv Ophthalmol 57: 347-370, 2012.

[7] WHO Global data on visual impairments 2010. www.who.int/blindness/GLOBALDATAFINALforweb.pdf.

[8] Wilkinson CP, Ferris FL 3rd, Klein RE, Lee PP, Agardh CD, Davis M, Dills D, Kampik A, Pararajasegaram R, Verdaguer JT; Global Diabetic Retinopathy Project Group. Proposed international clinical diabetic retinopathy and diabetic macular edema disease severity scales. Ophthalmology 2003; 110 (9): 1677-1682.

[9] Shaw JE, Sicree RA, Zimmet PZ: Global estimates of the prevalence of diabetes for 2010 and 2030. Diabetes Res Clin Pract 2010, 87: 4-14.

[10] Hall V, et al., Diabetes in Sub Saharan Africa Epidemiology and public health implications. A systematic review. BMC Public Health, 2011. 11: 564. doi: 10.1186/1471-2458-11-564 PMID: 21756350.

[11] Umoh V, and Abraham E: Prevalence of diabetic retinopathy in diabetes mellitus patients attending a tertiary eye clinic in Uyo South- South Nigeria. Ibom Medical Journal Vol. 6 No. 2 August, 2013.

[12] Lawan A, Mohammed TB. Pattern of diabetic retinopathy in Kano, Nigeria. Ann Afr Med 2012; 11: 75-9.
[13] Liu L, Wu J, Yue S, Geng J, Lian J, Teng W et al. Incidence Density and Risk Factors of Diabetic Retinopathy Within Type 2 Diabetes: A Five-Year Cohort Study in China (Report 1). International Journal of Environmental Research and Public Health. 2015; 12 (7): 7899-7909.

[14] Ibrahim M: Impact of Age, Duration and Control of Diabetes on Risk of Diabetic Retinopathy among Sudanese Diabetic Patients in Khartoum, Sudan- 2016: Hospital based CrossSectional study International Journal of Sciences: Basic and Applied Research (IJSBAR) (2017) Volume 33, No 1, pp 68-75.

[15] Chisha Y, Terefe W, Assefa H, Lakew S (2017) Prevalence and factors associated with diabetic retinopathy among diabetic patients at Arbaminch General Hospital, Ethiopia: Cross sectional study. PLoS ONE 12 (3): e0171987. doi: 10.1371/journal.pone.0171987.

[16] Khandekar R, J Al Lawati, A. J Mohammad, A Al Raisi, 2003. Diabetic retinopathy in Oman; A hospital based study [online] Available from: http://www.pubmedcentral.nih.gov/articlerender.fcgi?tool=pub medandpubmedid $=12928265$.

[17] C. R. Cleland et al: Diabetic retinopathy screening in Tanzania Tropical Medicine and International Health. volume 21 no 3 pp 417-426 march 2016.

[18] Ahmed RA, Khalil SN, Al-Qahtani MA. Diabetic retinopathy and the associated risk factors in diabetes type 2 patients in Abha, Saudi Arabia. J Fam Community Med 2016; 23: 18-24.

[19] Burgess PI, Allain TJ, García-Fiñana M, Beare NA, Msukwa G, Harding SP. High prevalence in Malawi of sightthreatening retinopathy and visual impairment caused by diabetes: identification of population-specific targets for intervention. Diabet Med 2014; 31 (12): 1643-1650.

[20] Jingi AM, Noubiap JJ, Essouma M, Bigna JJ, Nansseu JR, Ellong A, Mvogo CE. Association of insulin treatment versus oral hypoglycaemic agents with diabetic retinopathy and its severity in type 2 diabetes patients in Cameroon, sub-Saharan Africa. Ann Transl Med 2016; 4 (20): 395.

[21] Ting DS, Cheung GC, Wong TY. Diabetic retinopathy: global prevalence, major risk factors, screening practices and public health challenges: a review. Clin Exp Ophthalmol 2016; 44 (4) 260-277.

[22] YAU J W. et al: Global prevalence and risk factors of Diabetic Retinopathy. DIABETES CARE, VOLUME 35, MARCH 2012.

[23] Sharew G, Ilako DR, Kimani K, Gelaw Y. Prevalence of diabetic retinopathy in Jimma University Hospital, Southwest Ethiopia. Ethiop Med J 2013; 51 (2): 105-113.

[24] Mathenge W, Bastawrous A, Peto T, Leung I, Yorston D, Foster A, Kuper H. Prevalence and correlates of diabetic retinopathy in a population-based survey of older people in Nakuru, Kenya. Ophthalmic Epidemiol 2014; 21 (3): 169-177.

[25] Ashaye A, Arije A, Kuti M, Olusanya B, Ayeni E, Fasanmade A et al. retinopathy among type 2 diabetic patients seen at a tertiary hospital in Nigeria: a preliminary report. ClinOphthalmol 2008March; 2 (1): 103-108. 